\title{
Amigos son los amigos: Pílades y el coro de argivas en Orestes de Eurípides
}

\author{
Friends will be friends: Pilades and the Chorus of Argives in Euripides' Orestes
}

Cecilia J. Perczyk*

CONICET - Universidad de Buenos Aires - Universidad Nacional de Hurlingham -

Universidad Nacional de San Martín, Argentina

ceciliaperczyk@hotmail.com

Did http://orcid.org/0000-0003-3521-5784

\section{Resumen:}

En el presente trabajo propongo estudiar las relaciones de philia en la tragedia Orestes de Eurípides, haciendo foco en las expectativas respecto de la forma de conducirse que supone el hecho de ser varón o mujer. Para ello, en primer lugar, analizaré el vínculo entre el protagonista y Pílades, quien no teme el contacto con Orestes y consigue evitar que se suicide. Se trata de una diferencia notable respecto del accionar de Menelao, pariente de sangre de los hijos de Agamenón, que parece llegar a Argos para salvar a sus sobrinos, pero finalmente conspira contra ellos. Luego abordaré la relación de Electra con el Coro, destacada desde el punto de vista formal, ya que la párodo y el tercer estásimo constituyen diálogos líricos. La comparación entre la interacción de las argivas y el modelo de Pílades y Orestes permitirá indagar la incidencia de las mujeres en la trama.

Palabras Clave: Amistad, Tragedia, Eurípides, Orestes.

\section{Abstract:}

In the present work, I propose to study the relations of philía in Euripides' Orestes, focusing on the gender of the characters. First, I will analyze the link between the protagonist and Pilades, who does not fear the contact with Orestes and manages to avoid suicide. This is a remarkable difference regarding the actions of Menelaus, a blood relative of the sons of Agamemnon, who seems to arrive in Argos to save his nephews, but finally conspires against them. Then I will approach Electra's relationship with the chorus, standing out from the formal point of view since the parodos and the third stasimon constitute lyrical dialogues. The comparison between the interaction of the Argives and the model of Pilades and Orestes will allow investigating the incidence of women in the plot.

KeYwords: Friendship, Tragedy, Euripides, Orestes.

\section{INTRODUCCIÓN}

En Orestes de Eurípides se representan los días posteriores al asesinato de Clitemnestra. Confinados en el palacio, los hijos de Agamenón esperan que la asamblea decida su destino. El vínculo entre Orestes y Pílades, considerado ejemplar en la literatura y en la filosofía, juega un papel central en la trama. ${ }^{1} \mathrm{El}$ joven originario de la Fócide no teme el contacto con Orestes, contaminado por el crimen, y consigue evitar que no se suicide con un argumento que incluye la ejecución de un nuevo asesinato, el de Helena. Pílades se diferencia de Menelao, pariente de sangre de Orestes y Electra, que parece llegar a Argos para salvar a sus sobrinos pero, finalmente, conspira contra ellos por sus deseos de reinar en la ciudad. A diferencia del rey de Esparta, que

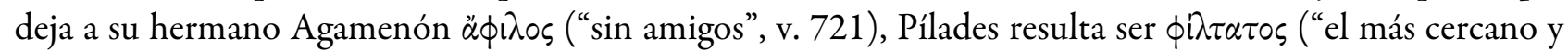
querido”, v. 725), para Orestes. Sin embargo, no se trata de la única relación de amistad representada en la obra. $^{2}$ Las argivas del coro no solo comparten los lamentos de Electra, sino que ayudan a los conspiradores a cometer el crimen de Helena vigilando el camino. ${ }^{3}$

En el presente trabajo propongo realizar un estudio de la relación del protagonista de la tragedia con Menelao, y luego los vínculos de amistad entre Pílades y Orestes, seguido por el de Electra con el Coro, haciendo foco en las expectativas respecto de la forma de conducirse que supone el hecho de ser varón o mujer. Se distinguen demostraciones de afecto en el vínculo con Pílades y en el de Electra con las argivas, 
que se denominan entre sí $\phi \grave{\lambda}$ os o $\phi i \lambda \alpha$ según sea el caso. Asimismo, los personajes se muestran dispuestos a acudir en ayuda del otro más allá de la retribución, uno de los signos fundamentales de la amistad como la entendemos en la actualidad. ${ }^{4} \mathrm{El}$ análisis de los puntos en común permitirá comprender la incidencia de las mujeres en la trama de Orestes. Sobre esta cuestión la crítica tiene opiniones divergentes porque, por un lado, se discute la injerencia en la acción de los coros en las tragedias de Eurípides, y, por otro lado, no suele esperarse que las mujeres cumplan un papel activo debido a una lectura sobre el género femenino en la Atenas clásica que sostiene que se trataba de seres destinados al silencio y la reclusión. ${ }^{5}$

\section{Menelao y Orestes}

Tras presenciar la escena de la alucinación de Orestes, en la que cree ser atacado por las Erinias, el público asiste a un segundo episodio, excepcionalmente largo, que incluye cuatro escenas y la aparición de otros tres personajes: Menelao, Tíndaro y Pílades. La primera escena se compone de un diálogo esticomítico entre tío y sobrino. Ante la pregunta del Atrida sobre si alguien lo ayudó cuando comenzaron los ataques de

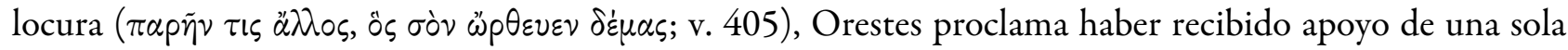

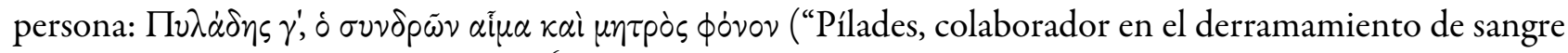
y el asesinato de mi madre", v. 406). ${ }^{6}$ La línea funciona como un anuncio de la escena siguiente, en la que el joven oriundo de la Fócide efectivamente sostendrá a Orestes. El heredero del trono de Argos otorga a Pílades el mismo atributo que a sí mismo: el de ser asesino de Clitemnestra. La atribución no se registra para otros personajes en la tragedia, si bien se adjudica responsabilidad en el crimen a Apolo y a Electra, por lo que podría hablarse de una identificación entre los dos personajes. El hecho de haber cometido el acto criminal juntos es importante porque en el apartado siguiente se verá que “actuar del mismo modo" constituye una de las características fundamentales de la amistad según la definición ofrecida por Orestes.

A continuación cito la breve rhêsis que cierra el diálogo entre Menelao y su sobrino, un momento de dilación que prepara la sorpresiva llegada de Tíndaro: ${ }^{7}$

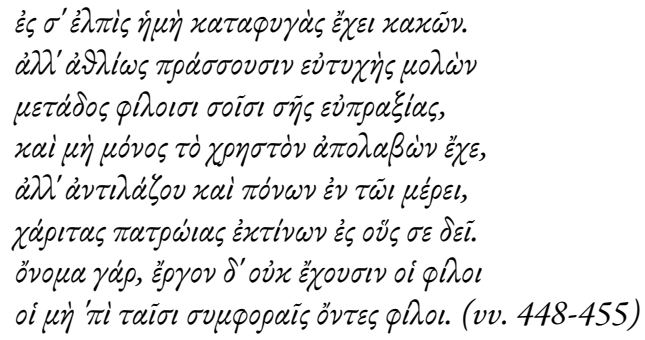

En ti mi esperanza tiene un refugio de los males. Pero, habiendo llegado feliz, comparte la dicha con tus amigos, que son desdichados, y no tomes [para ti] solo el beneficio que conseguiste, sino que participa también en la parte de los pesares, pagando los favores de mi padre a quienes debes. Pues de amigos [solo] tienen el nombre, y no la conducta, los amigos que no lo demuestran en las desgracias.

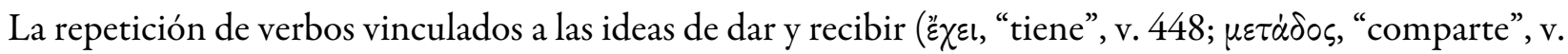

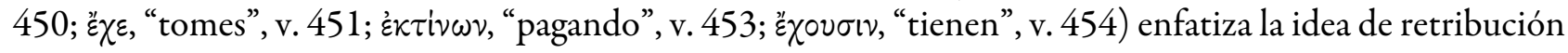
(Willink, 1986, p. 161). Es evidente que se juegan cuestiones vinculadas a la reciprocidad en la relación de Orestes con Menelao, que son justamente parientes de sangre. ${ }^{8}$ En este sentido, el pasaje se ubica en consonancia con la teoría más aceptada sobre la concepción de la philía en el pensamiento griego, en la que se sostiene que se trata de una serie de obligaciones y deberes recíprocos entre individuos. ${ }^{9}$

Sin embargo, Orestes no solo reclama una deuda sino que solicita a su tío que comparta la prosperidad (vv. 651-657), sin tomar en cuenta el beneficio antes obtenido que consiste en haber recibido ayuda para buscar a su esposa Helena en Troya (Konstan, 2006, p. 181). El hijo de Agamenón entiende que tiene derecho a 
esperar la ayuda de Menelao en tiempos difíciles independientemente de los favores recibidos de su padre. ${ }^{10}$ Por ello me inclino por Konstan (1997, p. 9) que, a diferencia de la opinión mayoritaria, ${ }^{11}$ le otorga al concepto de amistad en el periodo clásico una autonomía relativa de la economía y otras funciones sociales, y entiende que constituye una función comparable al estatuto que tiene en la actualidad. ${ }^{12}$

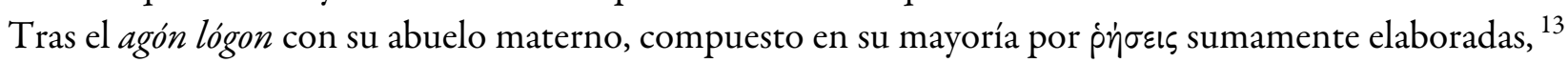
Orestes insiste en el pedido de retribución al Atrida: ${ }^{14}$

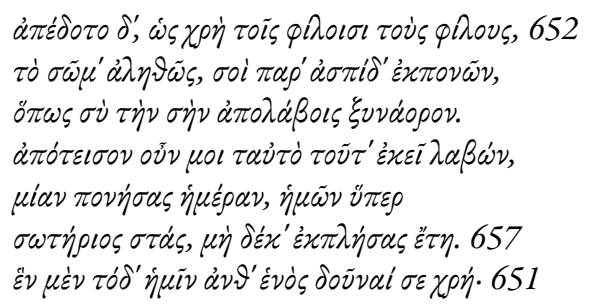

$\mathrm{Y}$ [mi padre] puso realmente a disposición, como es necesario [que hagan] los amigos con sus amigos, su cuerpo, esforzándose por ti junto a su escudo, para que tú recuperaras a tu esposa. Págame entonces eso mismo que antes recibiste, esforzándote un solo día, erigiéndote [como] salvador para nosotros, no empleando [para eso] diez años. Es necesario que nos des solo una cosa a cambio de otra.

Aquí el joven no insiste en la demanda desinteresada sino que comienza por indicar el favor recibido y acota que Agamenón puso en riesgo su vida al acompañarlo a Troya. Luego le reclama ayuda, ante lo cual Menelao primero reconocerá su validez (vv. 682-686), pero rápidamente expresará su negativa a llevar adelante el pedido. Justificará su accionar por falta de dýnamis (vv. 687-690), incluso dirá que puede intentar ayudarlo con la sophia (vv. 709-711).

\section{Pílades y Orestes}

Antes de analizar en particular la participación de Pílades en Orestes consideraré su presencia en el escenario trágico ateniense. El joven oriundo de la Fócide aparece por primera vez en Coéforas de Esquilo, donde se lo escucha decir solo tres versos (vv. 900-903). La breve intervención resulta rotunda, ya que consigue su cometido: que el hijo de Agamenón asesine a su madre. En Electra de Sófocles, si bien no entra en la categoría de agonista, se sobreentiende su función por las reiteradas apelaciones y el uso de la primera persona plural por parte de Orestes que señala que Pílades lo acompañó en todo momento. Ahora bien, en las obras de Eurípides el personaje asume diferentes papeles en cada una de las representaciones vinculadas al mito del heredero de Argos, que son Electra, Orestes e Ifigenia entre los tauros. Su presencia resulta mucho más sustancial que en las obras de sus predecesores. En Electra no aparece entre los personajes de la obra, pero los hijos de Agamenón y el mensajero destacan su hombría y la ayuda ofrecida para cumplir los designios de Apolo. En Orestes se verá en detalle que Pílades, no solo permanece junto a él, sino que lo aconseja en los momentos clave y acuerdan de qué modo actuar. La influencia en este caso es de tal magnitud que podría decirse incluso que dirige la trama de la segunda parte de la obra. Por último, en Ifgenia entre los tauros, exhorta al hijo de Agamenón a cumplir los designios divinos y además esboza el plan para robar la estatua de Ártemis. Como conclusión, Forte (1998, p. 60) destaca que el personaje de Pílades cumple dos funciones en las obras de los tres trágicos: cuando no habla, se lo invoca y se lo incluye en los discursos de los otros personajes, y en el momento que habla su discurso adquiere el poder del lógos. Se menciona el nombre del personaje en Coéforas tres veces, dos en Electra de Sófocles, ocho en Electra de Eurípides, quince en Orestes y diez en Ifigenia entre los tauros. Las menciones confirman su importancia en la trama, aun cuando no aparece en la nómina de personajes.

En Ifigenia entre los Tauros (vv. 917-918) se presenta a Estrofio, el padre de Pílades, como el esposo de una hermana de Agamenón y Menelao, con lo cual además de amigos, los jóvenes son primos hermanos. ${ }^{15}$ 
En Orestes se alude a la relación sanguínea de manera indirecta. ${ }^{16} \mathrm{Al}$ entrar en escena, Pílades se dirige al protagonista de la tragedia diciendo que es el más querido de sus coetáneos entre los amigos y los parientes

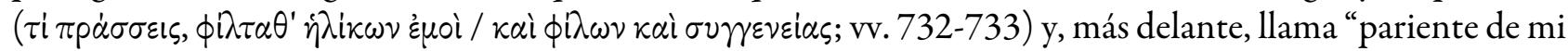

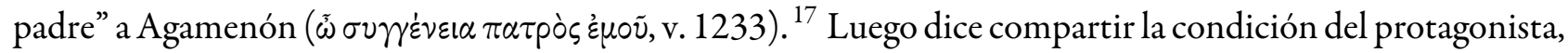

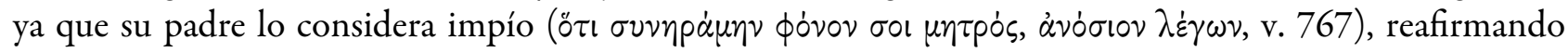
el atributo de asesino de Clitemnestra dado por Orestes (v. 405), antes comentado. Electra en el prólogo (vv. 32-33) había anticipado las declaraciones de Pílades (v. 767) al señalar su participación en el crimen. Ahora bien, el hecho de que el joven llegue a Argos porque fue echado por su padre implica que su condición es similar a la de su amigo, de manera que se potencia la comunión y la solidaridad entre los personajes (Medda, 2011, p. 231). Por otra parte, el dato permite conjeturar que dejó solo a su amigo tras el asesinato de Clitemnestra. ${ }^{18}$

El segundo episodio de Orestes cierra con un diálogo en tetrámetros trocaicos entre los dos jóvenes. Luego de informarse acerca de la situación en Argos, el joven oriundo de la Fócide dice que cuidará a Orestes ( $\dot{\alpha} \lambda \dot{\alpha}$

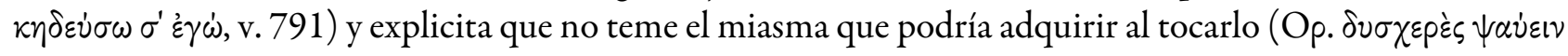

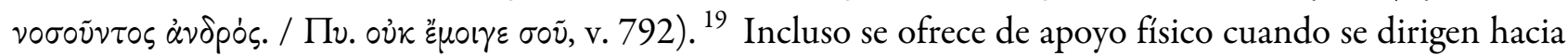
la asamblea: "ahora apresúrate, para que el voto de los argivos no te condene antes, habiendo apoyado en

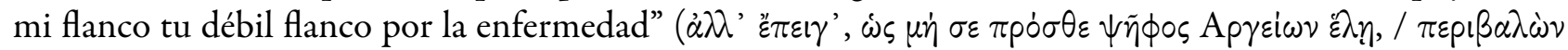

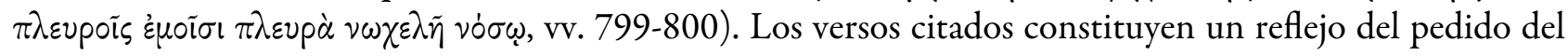
protagonista a Electra, antes de padecer la alucinación: "coloca tu flanco en mi flanco y aparta el cabello seco

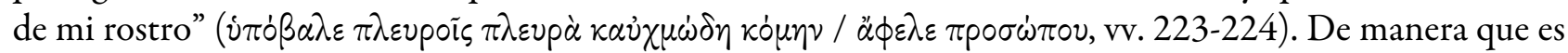
posible establecer un paralelismo entre la relación de los amigos y la de los hermanos que se ha interpretado como la expresión de la naturaleza problemática del vínculo entre Pílades y Orestes, debido a que Electra cuida a su hermano por tener un estatus inferior por su género sexual, pero no coincide con mi propuesta en tanto no considero que los vínculos resulten problemáticos en el sentido mencionado. ${ }^{20}$ Por otra parte, Medda (2011, p. 42) señala el hecho de que en el teatro griego no constituía una norma que los personajes se tocaran entre sí, por lo cual el hecho adquiere una fuerte carga emotiva. Además, la disponibilidad hacia Orestes por parte de la joven y Pílades permite remarcar la actitud mezquina de Tíndaro y Menelao. ${ }^{21}$

Un sector de la crítica evaluó de forma negativa la relación entre Pílades y Orestes (Verrall, 1905, pp. 234 y ss.; Smith, 1967; Burnett, 1971, pp. 213-215; Hartigan, 1987, pp. 129-132, y Theodorou, 1993, p. 43) por conducir a la ejecución de un nuevo crimen. En cambio, otro sector destacó el papel positivo de la philía en la obra y, además, diferenció la ayuda recibida por parte de Pílades en la primera parte, que le permite a Orestes lidiar con sus conflictos internos (la sýnesis), y el dispositivo (mechánema) de la segunda parte que lo salva de los peligros externos (Garzya, 1962, pp. 108-118). ${ }^{22}$ Por mi parte, acuerdo con la segunda postura, en tanto considero que evaluar de forma negativa la relación porque conduce a la ejecución de otro asesinato es una argumentación fundada en cuestiones morales que no se centra en el sostén afectivo que representa Pílades para Orestes desde el punto de vista dramático. Además, no hay que olvidar que dañar al enemigo constituía un hecho aceptado en la cultura griega clásica (West, 1987, pp. 33-34). ${ }^{23}$

Pílades proclama su indiferencia respecto de la opinión de la multitud al afirmar que no se avergüenza

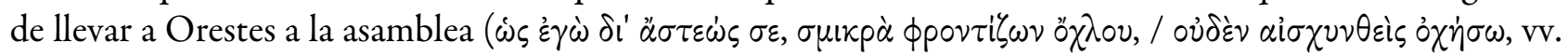
801-802). El heredero de Argos cierra la escena con una sentencia:

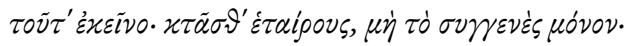

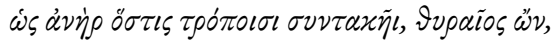

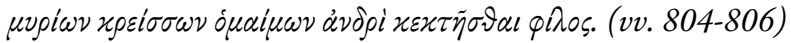

De esto se trata, tener compañeros, no solo relaciones familiares. Porque tener como amigo un varón que se identifica con los modos [de ser de uno], aunque sea un extraño, es mejor para un varón que numerosos parientes. 
Los sucesos de la tragedia le mostraron a Orestes que los lazos de parentesco no constituyen un apoyo estable y confiable, pero que puede obtener ayuda sincera y desinteresada de otros, como Pílades, que es un

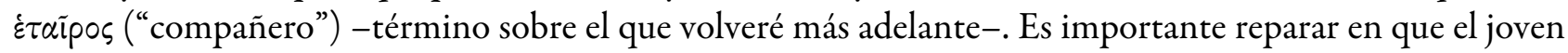
señala como un rasgo de la amistad el hecho de compartir la forma de actuar, hecho demostrado en la tragedia.

Luego del segundo estásimo, un lamento en el que el Coro inscribe el asesinato de Clitemnestra en la tradición familiar de los Atridas, llega el mensajero. El esclavo cuenta a Electra, a quien siempre la acompañan las argivas desde la orkhéstra, lo acontecido en la asamblea. Resulta fundamental para el análisis el siguiente detalle ofrecido por el mensajero:

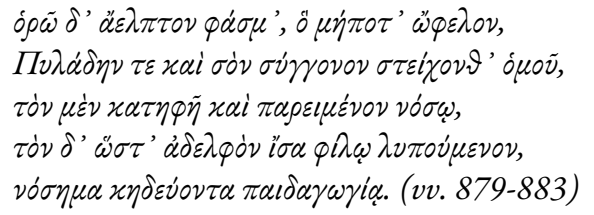

Y veo una aparición inesperada, que nunca hubiera deseado, a Pílades y a tu hermano caminando juntos. Uno con los ojos abatidos y debilitado por la enfermedad, el otro, sufriendo como un hermano igual que su amigo, haciéndose cargo de su enfermedad, asistiéndolo como a un niño.

No hay dudas de que Pílades es incondicional para Orestes. A su vez, los versos citados nos ofrecen una descripción del estado de abatimiento padecido por el protagonista de la tragedia.

El mensajero cierra su relato contando cómo Orestes se fue de la asamblea:

$\pi \circ \rho \varepsilon v_{\varepsilon} \varepsilon \delta^{\prime} \alpha \dot{v} \tau \dot{\nu} \nu \dot{\varepsilon} x \varkappa \lambda \dot{\eta} \tau \omega \nu \ddot{\alpha} \pi 0$

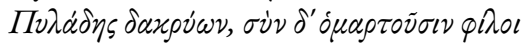

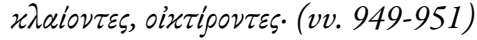

Y lo lleva lejos de la asamblea, Pílades, derramando lágrimas, y los amigos los acompañan gimiendo, lamentándose.

Un cortejo de hombres acompaña al hijo de Agamenón y comparte su dolorosa situación, la sentencia a muerte. ${ }^{24}$ Ahora bien, resulta llamativo que un grupo de varones se lamente de ese modo porque se trata de una acción típicamente femenina. En la cultura griega las mujeres eran las encargadas del planto, un aspecto clave de la procesión funeraria. ${ }^{25}$ Además, a los versos citados sigue una monodia a cargo de Electra y el Coro, un lamento funerario en el que lloran por la extinción de la casa de los Atridas, que funciona como una continuación del lamento de los hombres, de modo que se conforma una suerte de planto extendido.

En el final de su thrênos, las argivas indican la llegada al palacio de Orestes acompañado de su amigo. Luego de un diálogo entre los hermanos, los jóvenes hablan sobre la muerte y la amistad (vv. 1071-1099). ${ }^{26}$ El hijo de Estrofio expresa que, debido a que mataron juntos a Clitemnestra, debe sufrir lo mismo que el matricida

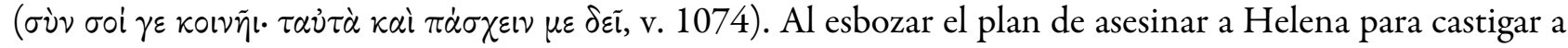
Menelao por traicionarlos logra que Orestes postergue el suicidio (vv. 1086-1091). Tras escucharlo, el joven

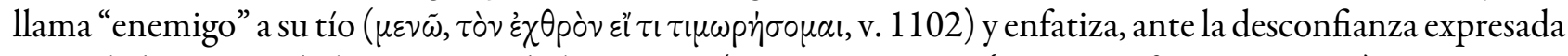

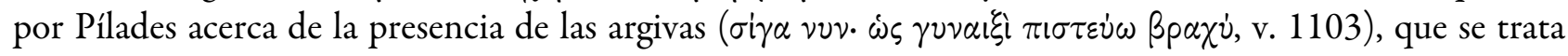

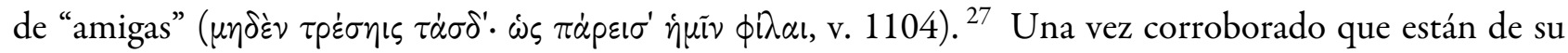
lado, Pílades expone, a partir de las preguntas de Orestes, cómo matar a Helena (vv. 1105-1153). El Coro acepta en complicidad la propuesta y no duda en aseverar que se trata de una mujer digna de odio por haber

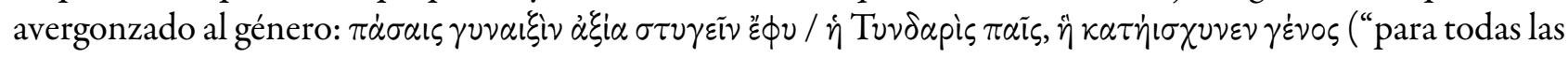
mujeres es digna de odio la hija de Tíndaro, la que deshonró a la raza”, vv. 1153-1154). ${ }^{28}$

Pese a la gravedad del plan, Orestes lo aprueba con inmediatez y alaba a su amigo: 


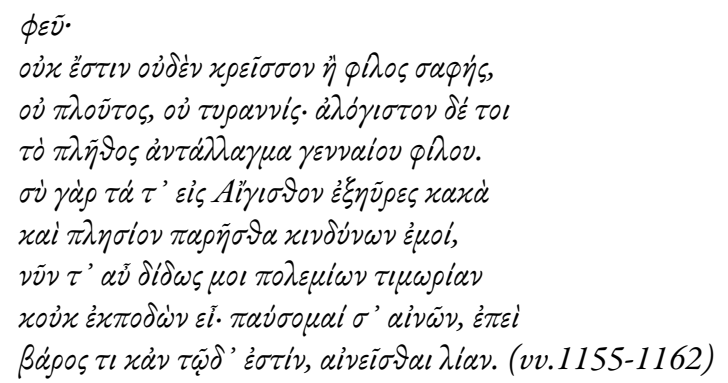

¡Ay! No hay nada mejor que un amigo verdadero, ni la riqueza, ni la tiranía. Déjame decirte, es irracional cambiar una multitud por un amigo noble. Pues tú ideaste males para Egisto y estabas a mi lado en los peligros, y ahora me ofreces de nuevo la venganza contra los enemigos, y no estás lejos. Dejaré de alabarte, puesto que hay una carga en esto, ser alabado excesivamente.

Konstan (1997, p. 60) sostiene que en la obra se explora la violencia producida cuando la lealtad personal se eleva por sobre los vínculos y obligaciones familiares que definen la vida del ciudadano ateniense. Recordemos que Orestes se representó en Atenas durante el 408 a. C. (siguiendo el escolio al v. 371 de la tragedia). Una ciudad que sufrió el golpe de estado del 411 a. C., denominado como el "de los Cuatrocientos", y que transitó la posterior restauración democrática.

El plan de asesinar a Helena y el secuestro de Hermíone, a lo que se suma la tentativa de incendiar el palacio, se han interpretado como el reflejo de la crisis de valores en Atenas producto de la inestabilidad cívica, consecuencia de la Guerra del Peloponeso. ${ }^{29}$ En este sentido, en la obra se registra un término de

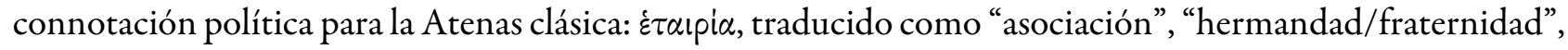
“compañerismo". ${ }^{30}$ En la segunda escena del tercer episodio, el sustantivo se emplea para indicar el vínculo

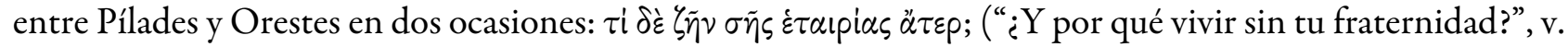

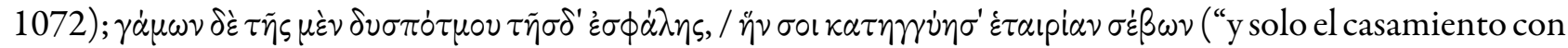
esta desafortunada se te frustró, a la que te prometí honrando nuestra fraternidad”, vv. 1078-1079). Además,

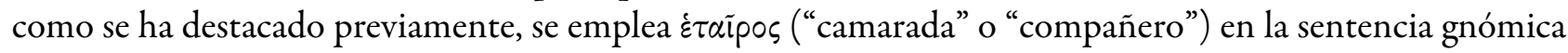

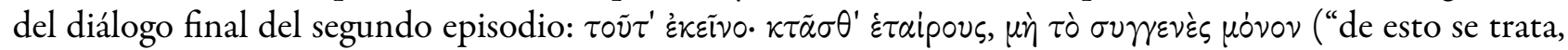
tener compañeros, no solo relaciones familiares”, v. 804). El verso citado constituye una línea emblemática de la obra por el contraste que expresa entre los vínculos de compañerismo y consanguinidad. ${ }^{31} \mathrm{Al}$ respecto, Willink (1986, p. 259) y Zimmermann (1998, p. 378) añaden que la desesperación de los conspiradores (Orestes, Pílades y Electra) en el final de la obra recuerda la conducta de los hetairíai oligarcas de la Atenas

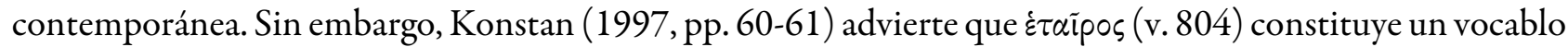

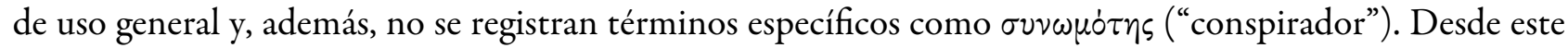
punto de vista, con el que acuerdo, la equiparación no es relevante.

\section{Electra y el coro de argivas}

Como en el caso de Orestes y Pílades, la relación entre Electra y el Coro se define a través del uso de la familia de palabras de philía. ${ }^{32}$ No solo ellas se denominan entre sí de ese modo sino que, como hemos visto, Orestes las considera sus $\phi i \lambda \alpha \iota$ (v. 1104). Podría decirse simplemente que las mujeres comparten lamentos, cantos que permiten amplificar el páthos, y, en cambio, los encuentros entre los amigos varones constituyen agônes, diálogos en los que la persuasión juega un papel fundamental. Sin embargo, a continuación citaré pasajes en los que se puede identificar cómo, dentro de los límites de las convenciones dramáticas, las argivas intervienen en la acción, ya sea animando, consolando, callando o vigilando. ${ }^{33}$

Tras dialogar con Helena en la segunda escena del prólogo, Electra adelanta el ingreso del Coro: 


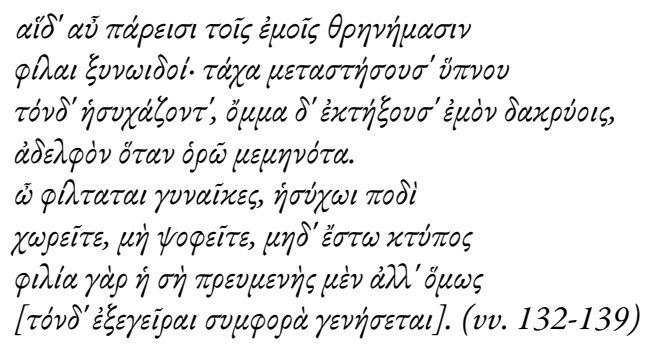

De nuevo están aquí, mis amigas que cantan al unísono mis lamentos. Rápidamente liberarán del sueño a este, que ahora reposa, y derretirán mis ojos en lágrimas cuando vea a mi hermano enloquecido. Queridísimas mujeres, avancen con paso silencioso, no hagan bullicio, y que no haya ruido. Pues su amistad es tierna pero sin embargo [que lo despierten será una desgracia].

La joven rompe la ilusión escénica al anticipar no solo el diálogo lírico de la párodo, al decir que las argivas cantarán con ella, sino también la escena sucesiva en la que Orestes se despierta y padece un ataque de locura (Di Benedetto, 1965, p. 33). El anuncio del ingreso del Coro constituye un procedimiento insólito para el género trágico (Di Benedetto, 1965, p. 33).

Las mujeres micénicas ingresan a la orkhéstra intentando cumplir el pedido de Electra: ${ }^{34}$

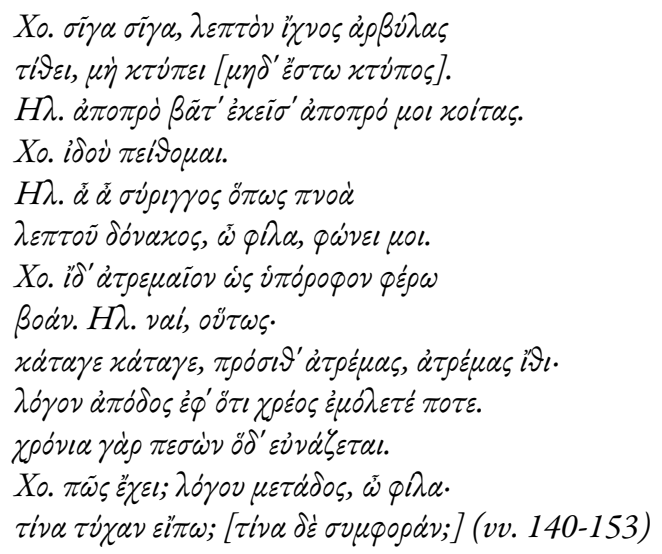

Coro: Silencio, silencio. Suave posa el paso del zapato, no hagas ruido [y que no haya ruido]. Electra: ¡Váyanse lejos de aquí, (háganme el favor), lejos del lecho!

Coro: Ya ves, obedezco.

Electra: Ah, ah, como el soplo de una siringa de delgada caña. ¡Amiga, háblame!

Coro: Mira, en calma, cómo elevo una suave (nota) de la pipa. ${ }^{35}$

Electra: Sí, así. ¡Vamos, vamos! Suavemente avanza, suavemente ven. Explícame por qué asunto vienen en este momento.

Pues, tras caer hace largo tiempo, este está acostado.

Coro: ¿Cómo está? ¡Comunícamelo, amiga! ¿De qué suceso hablaré? [¿Y de qué desdicha?]

$\mathrm{Al}$ mismo tiempo que les pide a las argivas que se retiren, Electra les solicita que hablen. Recordemos que la presencia del Coro en la orkhéstra supone un grupo de quince artistas cantando y bailando con acompañamiento musical. Por lo cual el pedido de silencio y alejamiento del lecho resulta incoherente y además cuestiona una de las funciones asignadas al coro que es la de consolar al personaje sufriente (Medda, 2011, p. 162). ${ }^{36}$ Además, desde un punto de vista meta-teatral, si las argivas efectivamente partieran y no cantaran, no podría comenzar la tragedia (Kim On Chong-Gossard, 2008, p. 124).

En la primera estrofa del tercer estásimo, Electra y las argivas se organizan del siguiente modo:

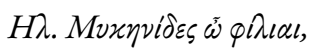

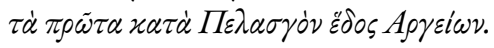

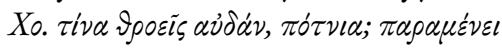

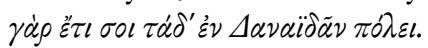




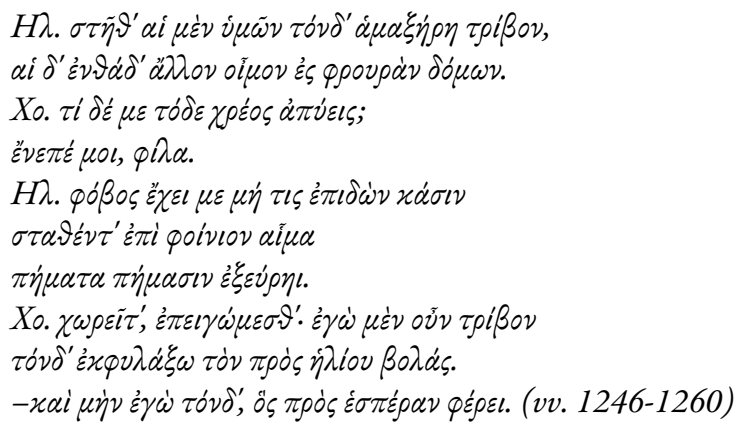

Electra: ¡Queridas mujeres micénicas! Primeras en la sede pelásgica de los argivos. Coro: ¿Qué discurso proclamas, señora? Pues aún este [título] permanece para ti en la ciudad de los dánaos. Electra: Vayan a colocarse, unas de ustedes, en el camino de los carros, y las otras, aquí, en el otro camino para vigilar la casa. Coro: ¿Y por qué [para cumplir] esta obligación me llamas? Dime, amiga.

Electra: Temo que alguien, viendo a mi hermano dispuesto para el sangriento asesinato, pueda añadir calamidades a las calamidades.

Coro: Vayan, apresurémonos. Yo ciertamente vigilaré este camino, que [lleva] a los rayos del sol.

-Y yo este, que lleva al oeste.

Los versos citados forman parte de la primera escena del desenlace. La forma es similar a la párodo pero con un tono diferente, ya que se ajusta a la nueva situación. La división en dos semicoros constituye un procedimiento frecuente en la obra de Eurípides, cuyo efecto a nivel espectacular debía ser notable. Si bien el conocimiento que tenemos sobre la puesta en escena es prácticamente nulo, podría conjeturarse que Electra se ubicaba en el centro de la escena de manera de poder hablarle a los dos grupos de mujeres (Di Benedetto, 1965, p. 241). El pasaje de acción conspiratoria, señala Navarro Noguera (2014, p. 46), recuerda las instrucciones militares: el corifeo y una parte de la "tropa" de mujeres vigilará una parte del camino, mientras la otra parte hará lo pertinente con relación al segundo camino. De esta manera se "masculiniza" el accionar de las mujeres, en tanto para los griegos la guerra era un ámbito estrictamente reservado para los hombres. La tropa de mujeres vigilando el camino funciona como el inverso del "coro" de hombres lamentándose con Orestes por su condena a muerte.

En lugar de cantos corales en la párodo y el tercer estásimo nos encontramos con diálogos líricos entre Electra y las argivas, pasajes donde justamente se acumulan los términos vinculados a la philía (vv. 140-207 y 1246-1310). ${ }^{37}$ El vínculo entre los personajes femeninos se denomina del mismo modo que la relación de Orestes y Pílades. ${ }^{38}$ Asimismo, se trata de mujeres nobles (dato indicado en los vv. 1246-1247), al igual que Electra, Orestes y Pílades. ${ }^{39}$ Las argivas no solo animan a Electra, en el tercer estásimo la hija de Agamenón les ordena que vigilen los dos caminos que conducen al palacio y ellas asienten. La complicidad del Coro en el asesinato de Helena y el secuestro de Hermíone implica una participación activa. No hay intriga en la tragedia griega sin la cooperación del coro, señala Barrett (1964, p. 294). ${ }^{40}$ Mastronarde (2010, p. 120) acota que en Orestes la connivencia se ajusta al colapso de los valores sociales y éticos que caracterizan la acción de esta obra.

Ahora bien, esto no implica que las argivas vean con buenos ojos el matricidio. En la antistrofa del segundo

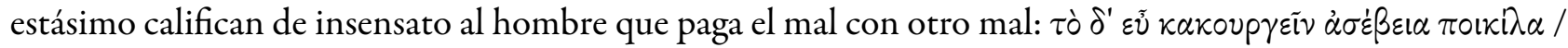
$\kappa \alpha \kappa \circ \phi \rho \dot{\nu} \nu \omega \nu \tau$ ' $\alpha \nu \delta \rho \tilde{\omega} \nu \pi \alpha \rho \dot{\alpha} \nu 01-$ / $\alpha$ ("hacer el mal por una buena razón es artificiosa impiedad y desvarío de hombres que piensan mal", vv. 823-825). ${ }^{41}$ Es decir, no apoyan la venganza como modus operandi. Parecerían entrar en contradicción al apoyar un nuevo crimen, pero en el caso de Helena lo justifican al decir que lo merece (vv. 1153-1154), como se ha comentado anteriormente.

En la antistrofa del éxodo, ${ }^{42}$ el Coro expone sus consideraciones acerca de lo que está sucediendo dentro del palacio real: 


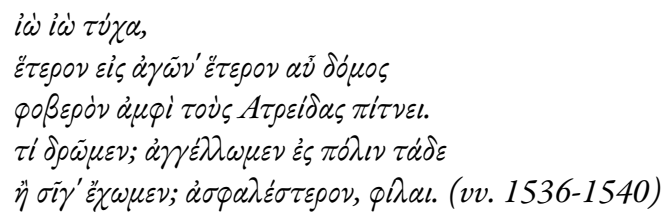

¡Ay, ay, [qué] desgracia! A otra, temible, hacia otra lucha de nuevo la casa alrededor de los Atridas cae. ¿Qué haremos? ¿Anunciaremos a la ciudad esto o permaneceremos en silencio? Es más seguro, amigas.

Ante la situación de crisis, las mujeres se preguntan qué hacer. Consideran una intervención activa pero luego desisten, parecen preferir el silencio y la resignación. Sin embargo, en los últimos versos reafirman su apoyo al alentar a los conspiradores a asegurar las puertas del palacio:

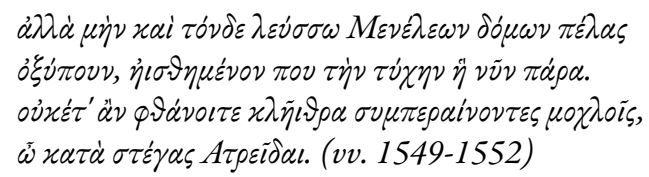

Y aquí veo a Menelao con paso veloz cerca de la casa porque se dio cuenta quizá de la desgracia que ahora sucede. Ya no podrían alcanzar los cerrojos asegurándolos con barras, oh, Atridas [que están] en la casa.

Con lo cual, la sympátheia de las argivas, expresada en primer lugar en la párodo respecto de Electra, no pasa a segundo plano con el curso de la acción por la intervención de personajes más eficaces, como Pílades, sino que se mantiene. Esto implica que ayudan al hijo de Agamenón y su compañero para vengarse de Menelao, plan que logra evitar el suicidio de los hijos de Agamenón. ${ }^{43} \mathrm{Al}$ mismo tiempo, diversos personajes en la obra afirman que Electra fue autora intelectual del crimen de Clitemnestra, ${ }^{44} \mathrm{y}$, además, es ella quien propone atacar a Hermíone (vv. 1191-1200). Por todo lo mencionado entiendo que en Orestes el papel de las mujeres, me refiero al colectivo de argivas compuesto por el Coro y a Electra, resulta fundamental para el avance de la trama trágica. ${ }^{45}$

\section{CONCLUSIONES}

A diferencia de la mayor parte de los trabajos sobre la philía en Orestes, enfocados en la cuestión de hetaireía y la situación histórico-social de Atenas en el momento de la producción de la tragedia, en el presente artículo se estudiaron los puntos en común de los vínculos de amistad representados. Desde el punto de vista expuesto, basado en la propuesta teórica de Konstan que otorga a la amistad una función comparable al estatuto que tiene en la actualidad, la relación de Orestes y Pílades no se lee de forma prototípica, sino como un espejo en el que se refleja la interacción de Electra y el Coro. Además de consolarse entre ellas, las mujeres actúan de forma efectiva, su conducta tiene una intención que se alcanza en el marco de la obra. Ellas participan del plan de asesinar a Helena y secuestrar a Hermíone, suceso fundamental a la hora de interpretar la obra porque la planificación del crimen provoca que Orestes decida no suicidarse. Si bien Apolo interviene como un deus ex machina en el final, considero que no es menor que el abandono del lecho de enfermo por parte de Orestes sea consecuencia del apoyo ofrecido por sus coetáneos: Pílades, Electra y las argivas del coro. ${ }^{46} \mathrm{El}$ hecho de que el joven recupere la posibilidad de actuar, incluso aunque sea para cometer otro homicidio, demuestra el valor de la amistad en el pensamiento griego y la capacidad curativa de la palabra. ${ }^{47}$

\section{REFERENCIAS}

Andrisano, A. M. (2017). La complicità di Pilade. Annali On-line Ferrara Lettere, 12, 75-90. 
Arnott, W. G. (1983). Tension, Frustration and Surprise: A Study of Theatrical Techniques in Some Scenes of Euripides' Orestes. Antichthon, 17, 13-28.

Bruit Zaidman, L. (1992). Las hijas de Pandora. Mujeres y rituales en las ciudades. En Duby, G. \& Perrot, M. (Dir.), Historia de las mujeres (T. I, pp. 373-419). Madrid: Santillana.

Burnett, A. P. (1971). Catastrophe Survived: Euripides' Plays of Mixed Reversal. Oxford: Clarendon Press.

Clarke Kosak, J. (1999). Therapeutic Touch and Sophokles' Philoktetes. HSPh, 99, 94-134.

Clarke Kosak, J. (2004). Heroic Measures. Hippocratic Medicine in the Making of Euripidean Tragedy. Leiden-Boston: Brill.

Conacher, D. J. (1967). Euripidean Drama. Myth, Theme and Structure. Toronto: University of Toronto Press.

Damen, M. (1990). Electra's Monody and the Role of the Chorus in Euripides' Orestes 960-1012. Transactions of the American Philological Association, 120, 133-145.

Duby, G. y Perrot, M. (Dir.). (1992). Historia de las Mujeres. T.1 (a cargo de P. Schmitt Pantel). Madrid: Taurus.

Dunn, F. N. (1996). Tragedy's End. Closure and Innovation in Euripidean Drama. Oxford: Oxford University Press.

Feaver, D. D. (1960). The Musical Setting of Euripides' Orestes. AJPh, 81(1), 1-15.

Foley, H. (2003). Female Acts in Greek Tragedy. Princeton: Princeton University Press.

Forte, N. B. (1998). Pílades o el estereotipo de la amistad. Circe, 3, 55-68.

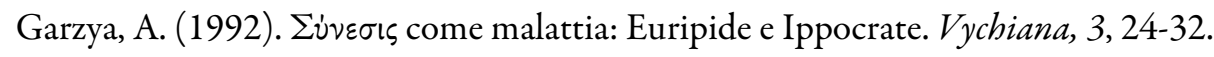

Goldhill, S. (1992). Reading Greek Tragedy. Cambridge: Cambridge University Press.

Greenberg, N. A. (1962). Euripides' Orestes: an Interpretation. HSPh, 66, 157-192.

Hall, E. (1993). Political and Cosmic Turbulence in Euripides' Orestes. En A. Sommerstein et al. (Eds.), Tragedy, Comedy, and the Polis. Papers from the Greek Drama Conference (Nottingham 18-20, July 1990, pp. 263-285). Bari: Levante.

Hartigan, H. (1987). Euripidean Madness: Herakles and Orestes. GßR, 34(2), 126-135.

Heath, M. (1987). The Poetics of Greek Tragedy. Stanford: Stanford University Press.

Kim On Chong-Gossard, J. H. (2006). Female Song and Female Knowledge in the Recognition Duets of Euripides. BICS, 87, 27-48.

Kim On Chong-Gossard, J. H. (2008). Gender and Communication in Euripides' Plays. Between Song and Silence. Leiden-Boston: Brill.

Kitto, H. D. F. (2003). Greek Tragedy. A Literary Study (1ª reimpresión, 6a ed.). London: Mathuen \& Co. Ltd.

Konstan, D. (1997). Friendship in the Classical World. Cambridge: Cambridge University Press.

Konstan, D. (2006). The Emotions of the Ancient Greek. Studies in Aristotle and Classical Literature. Toronto: University of Toronto Press.

Kyriakou, P. (1998). Menelaus and Pelops in Euripides' “Orestes”. Mnemosyne, 51(3), 282-301.

Lombardi, G. y Perczyk, C. J. (2019). El odio hacia la mujer como móvil de la tragedia en Orestes de Eurípides. Affectio Societatis, en prensa.

Longo, O. (1975). Proposte di lettura per l' Oreste di Euripide. Maia, 27, 265-287.

Mastronarde, D. J. (2010). The Art of Euripides. Dramatic Technique and Social Context. Cambridge: Cambridge University Press.

Navarro Noguera, A. (2014). La complicidad del coro femenino en Orestes. Philologica Urcitana, 11, 39-49.

Norwood, G. (1920). Greek Tragedy. London: Mathuen \& Co.

Pattoni, M. P. (1990). La sympatheia del coro nella parodo dei tragici greci: motivi e forme de un modello drammatico. SCO, 39, 33-82.

Peachin, M. \& Caldelli, M. L. (Eds.). (2001). Aspects of Friendship in the Graeco-Roman World. JRA Supplementary Series, 43. Portsmouth, R. I.

Perczyk, C. (2018). La locura en Heracles y Bacantes de Eurípides. Buenos Aires: Miño y Dávila. 
Pomeroy, S. (1998). Families in Classical and Hellenistic Greece. Oxford: Oxford University Press.

Rawson, E. (1972). Aspects of Euripides' Orestes. Arethusa, 5, 155-167.

Reinhardt, K. (1960). Die Sinneskrise bei Euripides. En Autor, Tradition und Geist (pp. 227-256). Göttingen: Vandenhoeck \& Ruprecht.

Smith, W. D. (1967). Disease in Euripides' Orestes. Hermes, 95, 291-307.

Synodinou, K. (1988.). Electra in the Orestes of Euripides. A Case of Contradictions. Métis, 3, 305-320.

Theodorou, Z. (1991). The Presentation of Emotions in Euripidean Tragedy. Tesis de doctorado. London: University. Inédita.

Theodorou, Z. (1993). Subject to Emotion. Exploring Madness in Orestes. CQ, 43(1), 32-46.

Verrall, A. W. (1905). Essays on four plays of Euripides: Andromache, Helen, Heracles, Orestes. Cambridge: University Press.

Whitlock Blundell, M. (1989). Helping Friends and Harming Enemies. A Study in Sophocles and Greek Ethics. Cambridge: Cambridge University Press.

Wright, M. (2008). Euripides: Orestes. London: Duckworth.

Zimmermann, B. (1998). Die Krise der Polis im Spiegel der attischen Tragödie. En J. V Bañuls et al. (Eds.), El teatre clássic al marc de la cultura grega i la seua péervivéncia dins la cultura occidental (pp. 369-380). Bari: Levante.

\section{Ediciones y Traducciones}

Apolodoro. (1950). Biblioteca (Trads. A. Freixas y S. I. De Mundo). Buenos Aires: Ffyl Uba.

Barrett, W. S. (Ed.). (1964). Euripides: Hyppolitos. Oxford: Oxford University Press.

Bywater, I. (Ed.). (1963). Aristotelis: Ethica Nicomachea. Oxford: Clarendon Press.

Chapouthier, F. \& Méridier, L. (Eds.). (2017). Euripide. Tragédies: Oreste. T. VI, $1^{\circ}$ partie (1959, $1^{\text {a }}$ ed.). Paris: Les Belles Lettres.

Di Benedetto, V. (Ed.). (1965). Euripidis: Orestes. Firenze: La Nuova Italia.

Diggle, J. (Ed.). (1994). Euripidis Fabulae. T. III. Oxford: Oxford University Press.

Dindorf, W. (1863). Scholia graeca in Euripidis tragoedias ex codicibus aucta et emendate. Vol. 2. Oxford: Oxford University Press.

Eurípides. (2007). Orestes (Trad. N. Andrade). Buenos Aires: Losada.

Lloyd-Jones, H. \& Wilson, N. G. (Eds.). (1990). Sophoclis Fabulae. Oxford: Oxford University Press.

Medda, E. (Ed. \& Trad.). (2011). Euripide: Oreste. Milano: BUR.

Murray, G. (Ed.). (1960). Euripidis Fabulae. T. III (1909, 1ª ed.). Oxford: Oxford University Press.

Page, D. L. (Ed.). (1972). Aeschyli Septem quae supersunt Tragoedias. Oxford: Oxford University Press.

Ross, W. D. (Ed.). (1964). Aristotelis: Ars rhetorica. Oxford: Clarendon Press.

West, M. L. (Ed.). (1987). Euripides: Orestes. Warminster: Aris and Phillips.

Willink, C. W. (Ed.). (1986). Euripides: Orestes. Oxford: Clarendon Press.

\section{INSTRUMENTA STUDIORUM}

Chantraine, P. (1968). Dictionaire Etymologique de la Langue Grecque. Paris: Klincksieck.

Liddell, H. G. \& Scott, R. (1996). Greek-English Lexicon (9a ed.). Oxford: Oxford University Press. 


\section{Notas}

* Cecilia J. Perczyk es Doctora en Letras Clásicas por la Universidad de Buenos Aires, Magíster en Estudios Clásicos (Facultad de Filosofía y Letras, Universidad de Buenos Aires) y Licenciada en Psicología (Facultad de Psicología, Universidad de Buenos Aires). Se especializa en filología y tragedia griegas. Actualmente desarrolla trabajos de investigación con una beca posdoctoral otorgada por CONICET. Es docente de literatura clásica en la Universidad Nacional de Hurlingham y en la Universidad Nacional de San Martín. Dirige actualmente dos grupos de investigación, uno orientado al estudio de la Orestía de Esquilo en clave de género (PIUNAHUR financiado por UNAHUR) y el otro sobre locura, emoción y crimen en el corpus fragmentario de la tragedia griega clásica (PICT 2017 financiado por Agencia Nacional de Promoción Científica y Tecnológica).

1 Cicerón (De finibus II.79), Marcial (Epigramas VI.11), San Agustín (Confesiones VI), entre otros.

2 El sustantivo $\phi i \lambda i \alpha$, junto con el verbo asociado $\phi i \lambda \dot{\varepsilon} \omega$, se emplea para indicar amor en términos generales. Ahora bien, $\phi i \lambda i \alpha$ también suele traducirse como "amistad" y el adjetivo $\phi i \lambda \circ \varsigma_{\text {, }}$ "querido", como "amigo" cuando cumple funciones como sustantivo. Siguiendo a Aristóteles en Ética Nicomáquea (8.12), el término $\phi i \lambda i \alpha$ indica tres categorías de relaciones: la comunitaria ( moderna, y la familiar ( $\sigma \nu \gamma \varepsilon v i \kappa \eta \dot{)}$. Recuérdese que, en el libro II de Retórica, Aristóteles aborda la cuestión del amor y su opuesto, el odio o la enemistad. En Orestes se registran más de setenta ocurrencias del término $\phi i \lambda i \alpha$ y vocablos que pertenecen a la misma área lexical. Para indicar la relación de Pílades y Orestes: vv. 733, 735, 794, 802, 804, 806, 882, 1072, 1079, 1082, 1095, 1096, 1155, 1157, 1244, 1405 y 1619; para hablar del vínculo entre Pílades, Orestes y Electra: vv. 299, 300, 310, 1054, 1190, 1192, 1244, 1300, 1346; para referirse a Electra y el Coro: vv. 133, 136, 138, 146, 153, $186,1104,1246,1249,1254,1271,1273,1353,1540$; para remitir a Menelao, que justamente no actúa como un amigo: vv. 424, 450, 454, 455, 475, 482, 628, 652, 665, 666, 667, 690,721, 740, 748, 1059, y para otros usos genéricos o remitir a otros personajes: vv. 97, 100, 211, 229, 372, 435, 627, 669, 870, 894, 896, 950, 1049, 1034 y 1337. Andrisano (2017, p. 82) advierte que se presenta un número muy elevado de ocurrencias y compuestos con $\sigma v v-$, hecho que resalta la relación de fuerte connivencia entre las figuras de Orestes, Electra y Pílades (ver, por ejemplo, vv. 767 y 1074), además de mostrar la búsqueda de otras complicidades, ya que el protagonista invoca a su padre como $\sigma \nu \lambda \hat{\eta} \pi \tau \omega \rho$ (v. 1230). Se trata de vivir o morir todos juntos, compartir en consecuencia los desastres (vv. 735, 865 y 1074), los crímenes (vv. 1098 y 1591 ) y la sepultura (vv. 1055 y 1067).

3 Recuérdese que se ha conservado un papiro del coro de Orestes (Papiro de Viena G 2315) con un pequeño fragmento musical que incluye una anotación vocal e instrumental de la antistrofa del primer estásimo. Al respecto puede consultarse Feaver (1960).

4 Para Greenberg (1962, p. 168) en la obra hay un contraste entre la philía inspirada por Orestes y Pílades y la sophía, en tanto práctica de la prudencia, encarnada por el Atrida. La adjudicación de un rasgo positivo a Menelao llama la atención, ya que la crítica en general suele remarcar su cobardía, incluso se habla de villanía (Burnett, 1971, pp. 186 y 206). Recuérdese que, desde Ilíada, es un protegido de su hermano Agamenón y carece de areté. Véase, por ejemplo, Ilíada XXVII.588.

5 Al respecto puede consultarse Duby \& Perrot (1992) y Foley (2003), inter alios multos.

6 Los pasajes citados de Orestes de Eurípides corresponden a la edición de Diggle (1994) y su traducción me pertenece en todos los casos.

7 Medda (2011: 200) explica que Eurípides introduce el personaje de Tíndaro en el momento que Orestes suplica a Menelao de manera que el encuentro entre abuelo y nieto se desarrolle ante el Atrida antes que este responda al pedido de su sobrino.

8 Se retoma la cuestión de la retribución en el final de la obra cuando Apolo declara que castigará a Neoptólemo (vv. 1656-1657).

9 Goldhill (1986, p. 82); Heath (1987, p. 73-74); Whitlock Blundell (1989, p. 32) y Belfiore (2000, p. 7), entre otros.

10 En desacuerdo con Konstan, Kyriakou (1998, p. 283) sostiene que en Orestes, donde los hijos de Agamenón llaman a Menelao $\phi \grave{\lambda}$ os y viceversa, entre tío y sobrinos no hay afecto en juego.

11 La propuesta de Konstan (1997) no ha sido bienvenida por la crítica posterior. Por ejemplo, en la mayor parte de los capítulos que componen Aspects of Friendship in the Graeco-Roman World (Peachin, 2001) se reduce el aspecto emocional de la relación de amistad entre el mundo greco-romano, y Belfiore (2000, pp. 20-21) discute punto por punto las afirmaciones de Konstan.

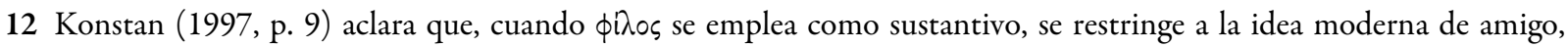
mientras que el sustantivo $\phi i \lambda i \alpha$ y el verbo $\phi i \lambda \varepsilon \tilde{\varepsilon} \nu$ cubren relaciones mucho más amplias que la amistad, incluyendo el amor entre los parientes y el afecto o la solidaridad entre asociados distantes, como miembros de la misma fraternidad o ciudad. Al respecto, Chantraine (1968, p. 1204) sostiene que el sustantivo $\phi i \lambda \circ s$ expresa la pertenencia a un grupo social 
y no una relación afectiva; aclara que el valor afectivo que tiene cuando cumple la función de adjetivo es secundario, aunque antiguo.

13 También encontramos aspectos vinculados a la retribución en la interacción con Tíndaro, ya que al divisar su llegada al palacio, Orestes expresa que no ha dado una buena retribución por su crianza a sus abuelos maternos al matar a Clitemnestra (vv. 459-469).

14 En los vv. 622-626 Tíndaro le deja en claro a su yerno Menelao que cualquier ayuda brindada a sus sobrinos le costará el trono de Esparta. Según el mito, el anciano, padre natural de Clitemnestra y adoptivo de Helena, había cedido en vida el gobierno de la ciudad a su yerno.

15 Según Apolodoro (Epitome VI.24-25), Electra entregó a Orestes a Estrofio para que lo cuidase y él lo crió con su hijo Pílades. Al alcanzar la madurez, siguiendo las indicaciones de Apolo, se dirigió a Micenas acompañado por Pílades para vengar la muerte de su padre. La adultez señalada por Apolodoro contrasta con la efebía referida en las obras de los trágicos.

16 En su relato de la asamblea, el mensajero indica que Pílades sufre, como si se tratara de un hermano, lo mismo que Orestes

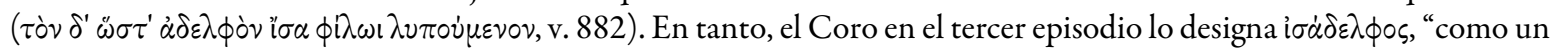

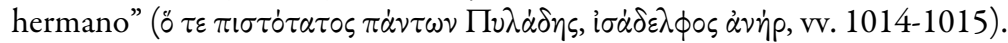

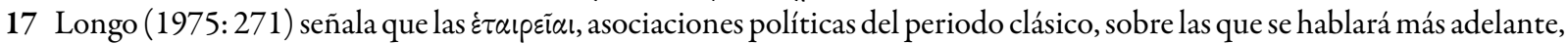
se caracterizaban por reunir individuos afines por edad, clase social y costumbres, por lo cual entiende que la presencia del término $\tilde{\eta} \lambda \_\xi$ (“de la misma edad”, v. 732) en la tragedia, además de calificar la amistad entre los personajes, debe ser leída en ese sentido.

18 En la tragedia no solo se atribuye participación y responsabilidad a Orestes en el matricidio. A continuación indico las diferentes atribuciones por orden de aparición. Electra dice que Apolo persuadió al joven de matar a su madre (vv. 165 y 191-193), pero también que ella y Pílades tuvieron parte en el crimen (vv. 28-33). Helena sostiene que el dios es el responsable del asesinato de Clitemnestra (vv. 75-76). En el diálogo lírico de la párodo, Electra dice al Coro que Febo dictaminó el asesinato (vv. 164-165). Orestes señala que si bien Electra aprobó el acto, él fue el ejecutor del crimen instigado por el dios (vv. 283-287) y ante Menelao dice que Apolo lo ordenó (v. 416). En la asamblea, según el mensajero, Orestes no implica a nadie más que a él mismo en el asesinato (v. 935). El Atrida no acusa a su sobrino de haber matado a Clitemnestra, más bien al contrario, ya que habla de los males que sufrió (vv. 375-376). Por su parte, Tíndaro ante Menelao solo implica a su nieto en los acontecimientos (vv. 492-541), pero al dialogar con Orestes acusa a Electra de ser la instigadora del crimen, hecho por el cual considera que ella merecería incluso un mayor castigo que su nieto (vv. 615-621). Ante su abuelo, Orestes se ubica primero como el único asesino de Clitemnestra (vv. 546, 562 y 572 ) y cierra el discurso afirmando haber seguido órdenes de Febo (vv. 591-599). Pílades aparece en Argos porque su padre Estrofio lo echó de la casa por haber colaborado en el asesinato (vv. 765 y 767). El Coro solo habla de Orestes como responsable en el segundo estásimo (vv. 824-843). El campesino, cuyo discurso relata el mensajero, solo se refiere al joven, al igual que el Coro (vv. 923-925). En el tercer episodio, el protagonista, luego de que el mensajero informa acerca de lo sucedido en la asamblea, enfatiza que él fue quien mató a su madre (v. 1073). Ante ello, Pílades aclara que cometieron el asesinato juntos (v. 1089). Cuando Orestes afirma que mató a su madre, en la plegaria a su padre (v. 1234), Pílades dice haber tocado la espada (v. 1235) y Electra se ubica como instigadora (v. 1236). Ahora bien, al asesinato de Clitemnestra se suma la planificación del de Helena, llevado adelante por Orestes y Pílades; si bien se trata de una propuesta del joven originario de la Fócide, el heredero de Argos la acepta rápidamente (vv. 1105-1106). El Coro habla de hombres en plural realizando el nuevo crimen (v. 1297). En el final, Orestes dice que Pílades colaboró en el nuevo asesinato (vv. 1535-1536). Menelao inculpa a los dos amigos de la muerte de su esposa (vv. 1565-1566). En cambio, Apolo vincula únicamente a Orestes en el crimen de Helena (vv. 1629-1630).

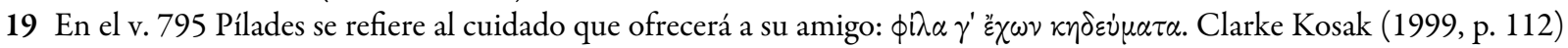
señala que el verbo $\kappa \eta \delta \varepsilon v ่ \omega$ (v. 791), junto con el sustantivo $\kappa \eta ่ \delta \varepsilon v \mu \alpha$ (v. 795), dirigen la atención hacia el vínculo de Pílades y Orestes porque, además de tener un sentido vinculado al cuidado y hacerse cargo del otro, son términos empleados para describir las relaciones de parentesco en tanto remiten a las alianzas producto de los matrimonios.

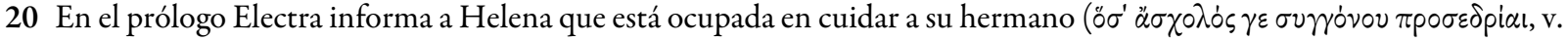
93). Luego se muestra en escena a la joven ayudándolo, especialmente durante el primer episodio (vv. 211-315). Además, hay reciprocidad en el vínculo: Orestes se preocupa por su hermana ni bien se recupera de la alucinación de las Erinias (vv. 268-306) y, tras ser informada que morirán por decisión del pueblo argivo, Electra solicita abrazar a Orestes, quien contesta diciendo que quiere retribuir abrazándola él también (vv. 1042-1051). Willink (1986, p. 120) define la función

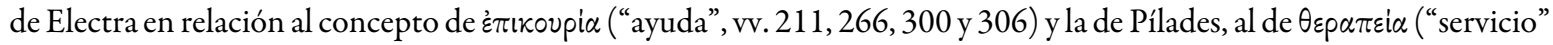
o "asistencia") y al de $\phi i \lambda i \alpha$. En tanto, Theodorou (1991, p. 101) sostiene que hay una diferencia fundamental entre la relación de Orestes con Electra y Pílades. El vínculo con su hermana no alcanza el nivel de unidad que comparte el joven con su amigo por ser incestuoso (vv. 1047-1051), sofocante (vv. 1027-1028 y 1031-1032), dependiente (vv. 307-315), de cuidado (vv. 217-218 y 221-222), e intrigante e influyente (vv. 1191-1206). 
21 Clarke Kosak (1999, pp. 103-105) analiza el valor terapéutico que tiene para el enfermo que su hermana lo toque en la escena de enloquecimiento (vv. 216-224).

22 La crítica se divide sobre la estructura de Orestes: están quienes, como Conacher (1967, p. 213), hablan de tres partes, y, por otro lado, están quienes sostienen una bipartición, como Wright (2008, pp. 32-33). Sin embargo, desde un punto de vista teórico, el problema de la unidad constituye una cuestión moderna que ignora las reglas de composición y los parámetros estéticos de la Antigüedad clásica.

23 Véase Whitlock Blundell (1989) que se dedica a la cuestión de ayudar a los amigos y dañar a los enemigos en las tragedias de Sófocles. En la introducción, donde se incluye una gran cantidad de bibliografía sobre el tema, la autora destaca el hecho de que la venganza y el compañerismo constituyen fuentes de placer.

24 Willink (1986, p. 238) interpreta la mención de los фìnoı como una sugerencia de la participación de Orestes en una

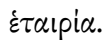

25 La mención de este cortejo de hombres ha llamado la atención de la crítica. Verrall (1905, p. 286) incluso llegó a decir que si son mencionados es porque aparecían junto a Orestes y Pílades en la escena siguiente (vv. 1012 y ss.). En contra de esta interpretación, Willink (1986, p. 238) y Medda (2011, pp. 253-254). Sobre la función central que cumple la voz femenina en los ritos funerarios puede consultarse, inter alios multos, Bruit Zaidman (1992, pp. 408-410) y Pomeroy (1998, pp. 106 y ss.).

26 Véase Medda (2011: 55) quien advierte que en Orestes la afirmación de los valores de amor fraternal y la amistad tiene la particularidad de realizarse en la esfera de la muerte. Electra expresa el deseo de que su hermano sea el encargado de matarla (vv. 1037-1038) y, unos versos después, pide ser enterrada con él (vv. 1052-1053); mientras que Pílades insiste con la idea de morir con su amigo (vv. 1089-1091 y 1098-1099).

27 Sobre los vv. 1103-1104 me enfocaré en el apartado siguiente.

28 Sobre la cuestión del odio hacia la mujer en Orestes, véase Lombardi \& Perczyk (2019).

29 Véase Rawson (1972, pp. 160-162), que se basa en Verrall (1905, p. 223); Hall (1993, pp. 270-271), y Wright (2008, pp. 103-106).

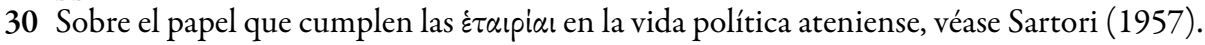

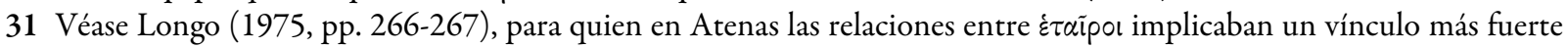
que entre $\phi \grave{i}$ ol. Entiende que Orestes constituye un caso paradigmático de la "sintomatología" social de la que habla

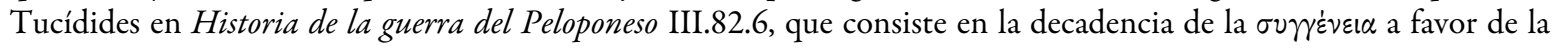

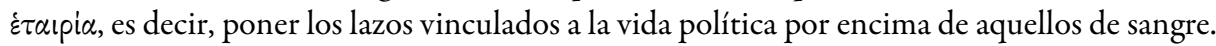

32 Véase nota 6. Sobre el papel de Electra en Orestes, Synodinou (1988) destaca la contradicción entre su intención de no entrometerse en los asuntos de los hombres por ser una virgen (vv. 26-27) y el modo de comportarse que tiene efectivamente en la obra. La autora explica que su intensa participación está en contra de las características tradicionales de una mujer por lo que se convierte en una figura similar a Clitemnestra y Helena, personajes a quienes criticó y que son los responsables de su difícil situación.

33 Damen (1990, p. 140) sostiene que la naturaleza de la amistad entre las mujeres resulta dudosa porque en los dos pasajes líricos citados la joven se muestra altanera e imperiosa con las argivas, quienes, aunque son aliadas, resultan ser ansiosas e insensibles ante las necesidades de los herederos de Agamenón. En cambio, para Navarro Noguera (2014), con quien acuerdo, la solidaridad del Coro con Electra se muestra a través de la palabra, la acción directa y el silencio.

34 Pattoni (1990, pp. 79-81) sostiene que Electra tiene por su hermano un sentimiento de solidaridad mucho más fuerte que la genérica compasión que sienten las argivas por ella, por lo que la función consolatoria, que en otras tragedias cumple el Coro, aquí la lleva adelante la hija de Agamenón.

35 La interpretación del sentido del adjetivo ítópoфov (v. 147) es difícil. Liddell \& Scott (1996) indican que el término es derivado de öpoфos, siguiendo el escolio al verso. Acuerdo con esta interpretación porque permite continuar las referencias musicales del verso anterior. Por otra parte, están quienes lo traducen como "que se encuentra bajo un techo” (Di Benedetto, 1965, p. 36; West, 1987, p. 192; Medda, 2011, p. 163, y Andrade, 2007, p. 64).

36 Es notable la semejanza con la escena de Heracles en la que Anfitrión pide silencio a los ancianos por temor a que despierten a su hijo (vv. 1043 y ss.), luego de haber matado a su mujer e hijos en un ataque de locura. Callar al Coro tiene un evidente matiz cómico en tanto su función consiste en bailar y cantar. En el caso de Orestes el procedimiento no se presenta de forma aislada, desde la Antigüedad se ha destacado la abundancia de recursos cómicos en la obra, cuestión que ha llevado a cuestionar si se trata de una tragedia. Están quienes sostienen que se trata de un melodrama, como Kitto (2003, pp. 311-312), West (1987, p. 27) y Andrade (2007, pp. 11-12), y quienes hablan de una tragicomedia, como Dunn (1996, p. 222). Los poetas cómicos de la época se mostraron particularmente interesados en la tragedia. Arnott (1983, p. 13) ofrece una sinopsis del interés por parte de los poetas cómicos en la obra.

37 El diálogo lírico entre un actor y el Coro es característico de la técnica dramática de Eurípides (Di Benedetto, 1965, p. 34). Véase Mastronarde (2010, pp. 88-152), con quien acuerdo, que considera que los coros en la producción de Eurípides, como también sucede en la de Sófocles, eran una parte esencial de la performance y de la generación de sentido, como lo habían sido desde los conjeturados comienzos del género. Esto no quita que haya habido una reducción gradual de su 
importancia indicada por la menor proporción de sus líneas con respecto a la duración total del drama, su subordinación a otros personajes y otras características, como la expansión de los cantos de los actores.

38 La crítica difiere respecto de la adjudicación de los vv. 960-1012: están quienes consideran que se trata de una monodia (Murray, 1960, pp. 198-200; Chapouthier \& Méridier, 2017, pp. 70-73; Di Benedetto, 1965, pp. 190-202, y Andrade, 2007, pp. 136-140); otros sostienen que se trata de una oda coral (Damen, 1990, p. 137, seguido por Kim On ChongGossard, 2006, p. 28); por último, un sector atribuye los vv. 960-981 al Coro y los vv. 982-1012 a Electra (Diggle, 1994, pp. 244-247; West, 1990, pp. 125-129, y Medda, 2001, pp. 255-260), e incluso se ha hablado de un lamento con una estructura antifonal (Willink, 1986, p. 240). Me inclino por un intercambio entre la joven y el grupo de argivas, ya que de ese modo se asemeja a los diálogos líricos de la párodo y el tercer estásimo.

39 Los coros femeninos, una tendencia en las obras de Eurípides, son particularmente apropiados para los conflictos domésticos, como sucede en el caso de Orestes (Mastronarde, 2010, p. 103). Para ver los porcentajes y la situación de los otros trágicos, consúltese Mastronarde (2010, p. 102).

40 A diferencia de Willink (1986, pp. 259 y 268), que sostiene la participación activa de las argivas, Andrade (2007, pp. 147 y 151-152) entiende que su injerencia en el desarrollo de la acción es mínima y señala que se trata de una característica de la producción de Eurípides.

41 A diferencia de Diggle (1994), Di Benedetto (1965, pp. 164-165) y Medda (2011, p. 241) mantienen el texto de los manuscritos donde figura $\alpha \tilde{u}$ (“a su vez”) en lugar de $\varepsilon \tilde{u}$.

42 Las argivas, con su canto, interrumpen la acción del éxodo en los momentos de mayor tensión dramática. La estrofa correspondiente aparece en los vv. 1353-1368.

43 Medda (2011, p. 45) destaca el hecho de que, a diferencia de las otras tragedias donde un personaje en condiciones extremas recibe ayuda de otro con el que mantiene un lazo afectivo - Heracles, Fenicias y Filoctetes-, el acto de solidaridad en Orestes no provoca un abandono del espacio escénico ni se ubica como momento conclusivo.

44 Véase nota 11.

45 Willink (1986, p. 278), en su comentario a los vv. en los que Electra propone secuestrar a Hermíone (vv. 1177-1203), sostiene que las artimañas femeninas juegan un papel importante en las intrigas trágicas.

46 La crítica suele interpretar el desenlace de la obra como un "final feliz" poco creíble. Cf., entre otros, Reinhardt (1960, pp. 255-256), para quien la improbabilidad evidencia falta de sentido, vinculado al nihilismo que caracteriza el periodo contemporáneo a Eurípides; Greenberg (1962, p. 190), que enfatiza el efecto disruptivo de la llegada del dios, y Hall (1993, pp. 284-285) que sostiene que la intervención divina constituye una ironía.

47 Sobre el poder del lógos en la recuperación de la locura, puede consultarse Perczyk (2018, pp. 345-365), que si bien aborda la cuestión en otras tragedias del mismo autor, Heracles y Bacantes, entiendo que puede ser de valor para la comprensión de Orestes. 